DOSSIÊ TEMÁTICO: Educação, currículo e juventudes: dilemas e desafios atuais

do1 https://doi.org/10.22481/praxisedu.v16i42.7339

\title{
FORMAÇÃO DOCENTE E PRÁTICA PEDAGÓGICA NO PROCESSO DE INCLUSÃO DO ESTUDANTE JOVEM COM DEFICIÊNCIA EM INSTITUIÇÕES DE ENSINO SUPERIOR
}

TEACHING TRAINING AND PEDAGOGICAL PRACTICE IN THE PROCESS OF INCLUSION OF YOUNG STUDENTS WITH DISABILITIES IN HIGHER EDUCATION INSTITUTIONS

\author{
FORMACIÓN DOCENTE Y PRÁCTICA PEDAGÓGICA EN EL PROCESO DE \\ INCLUSIÓN DE ESTUDIANTES JÓVENES CON DISCAPACIDAD EN \\ INSTITUCIONES DE EDUCACIÓN SUPERIOR
}

Patrícia Lessa Santos Costa Universidade do Estado da Bahia - Brasil

Nara Deoclecia Soares Modica Universidade do Estado da Bahia - Brasil

Carla Liane Nascimento dos Santos Universidade do Estado da Bahia - Brasil

\begin{abstract}
Resumo: O presente texto é resultado de uma pesquisa de campo que objetivou compreender como ocorre a formação docente e a prática pedagógica no processo de inclusão do estudante jovem com deficiência nas instituições de ensino superior do município de Barreiras-BA. A abordagem metodológica é qualitativa e o estudo de natureza descritiva-exploratória, do tipo Estudo de Caso. A coleta de informações foi realizada por meio de entrevista semiestruturada com os docentes e estudantes; na sequência foi realizada a análise de conteúdo baseada em Bardin (2011). A trajetória deste estudo teve como base os teóricos, Loss (2018), (2007), Moreira (2014), Rocha e Miranda (2009), Doutor (2016), Anastasiou e Pimenta (2014), dentre outros. Com esta análise foi possível verificar que a falta de conhecimento dos docentes sobre a concepção de inclusão educacional, é devido ao seu percurso formativo e que isso interfere nos modos do fazer pedagógico inclusivo, o que é referido pelos jovens estudantes. Do mesmo modo, o estudo aponta que os docentes atribuem possibilidades para que suas experiências sejam capazes de suscitar novas perspectivas acerca de uma ação transformadora, das potencialidades pessoais e sociais dos estudantes com deficiência.
\end{abstract}

Palavras-Chave: Ensino Superior, Jovem, Formação Docente, Educação Inclusiva, Práticas Pedagógicas.

Abstract: This text is the result of a field research that aimed to understand how teacher training and pedagogical practice occurs in the process of inclusion of young students with disabilities in higher 
education institutions in the city of Barreiras-BA. The methodological approach is qualitative and the study is of a descriptive-exploratory nature, of the Case Study type. Information was collected through semi-structured interviews with teachers and students; subsequently, content analysis based on Bardin (2011) was carried out. The trajectory of this study was based on the theorists, Loss (2018), (2007), Moreira (2014), Rocha and Miranda (2009), Doctor (2016), Anastasiou and Pimenta (2014), among others. With this analysis it was possible to verify that the teachers' lack of knowledge about the concept of educational inclusion is due to their formative path and that this interferes in the ways of inclusive pedagogical practice, which is mentioned by young students. In the same way, the study points out that teachers attribute possibilities so that their experiences are able to raise new perspectives about a transforming action, of the personal and social potential of students with disabilities.

Keywords: Higher Education, Young, Teacher Education, Inclusive Education, Pedagogical Practices.

Resumen: Este texto es el resultado de una investigación de campo que tuvo como objetivo comprender cómo se produce la formación docente y la práctica pedagógica en el proceso de inclusión de jóvenes estudiantes con discapacidad en instituciones de educación superior en la ciudad de Barreiras-BA. El enfoque metodológico es cualitativo y el estudio es de naturaleza descriptivaexploratoria, del tipo Estudio de caso. La información fue recolectada a través de entrevistas semiestructuradas con maestros y estudiantes; posteriormente, se realizó un análisis de contenido basado en Bardin (2011). La trayectoria de este estudio se basó en los teóricos, Loss (2018), (2007), Moreira (2014), Rocha y Miranda (2009), Doctor (2016), Anastasiou y Pimenta (2014), entre otros. Con este análisis fue posible verificar que la falta de conocimiento de los docentes sobre el concepto de inclusión educativa se debe a su camino formativo y que esto interfiere en las formas de práctica pedagógica inclusiva, que mencionan los jóvenes estudiantes. Asimismo, el estudio señala que los maestros atribuyen posibilidades para que sus experiencias puedan generar nuevas perspectivas sobre una acción transformadora, el potencial personal y social de los estudiantes con discapacidades.

Palabras clave: educación superior, Joven, formación docente, educación inclusiva, prácticas pedagógicas.

\section{Notas introdutórias}

Em um período de dez anos, isto é, entre 2004 e 2014, de acordo com os dados do Censo da Educação Superior do Instituto Nacional de Estudos e Pesquisas Educacionais Anísio Teixeira (Inep) ${ }^{1}$, o acesso de pessoas com deficiência ao ensino superior avançou no país, mas quando esses números são confrontados com os dados gerais de ingresso nas Instituições de Ensino Superior, essa participação ainda é ínfima. Em 2014, por conta de um conjunto de fatores, como a implantação de novas instituições e cursos e, ainda incentivo ao acesso por meio de iniciativas como o Programa Universidade para Todos (PROUNI), o Exame Nacional do Ensino Médio (Enem) e o Programa de Financiamento Estudantil (FIES), o número de matrículas no ensino superior cresceu consideravelmente e o ingresso de pessoas

\footnotetext{
${ }^{1}$ Instituto Nacional de Estudos e Pesquisas Educacionais Anísio Teixeira
} 
com deficiência nestas instituições também aumentou. Em relação ao Público Alvo da Educação Especial - $\mathrm{PAEE}^{2}$, o aumento foi de 518,66\%, atingindo 33.377 matrículas.

Diante deste quadro de desenvolvimento de matrículas no ensino superior do PAEE, é preciso que as instituições, cada vez mais, revejam algumas estratégias, inclusive mudanças conceituais, investimentos e suporte para os gestores, docentes e para os departamentos de atendimento, com a intenção de melhor atender este público, visando à permanência dos mesmos.

Esse fato apontado, do aumento de pessoas com deficiência matriculadas no ensino superior, impõe uma série de desafios para a educação inclusiva nos diversos níveis de ensino, pois, só o acesso não consolida a educação inclusiva. Diante disso, é necessário compreender como ocorre a formação docente e a prática pedagógica no processo de inclusão do estudante com deficiência nas instituições de ensino superior do município de Barreiras - BA. E ainda, identificar qual a concepção que os docentes apresentam acerca da educação inclusiva, bem como, investigar qual o sentimento dos docentes ao se depararem com estudantes com deficiência em sua sala aula e analisar se os docentes tiveram dificuldade em administrar metodologias para os estudantes com deficiência e por fim investigar como os estudantes jovens vivenciam a vida universitária.

Deste modo, o estudo aqui apresentado poderá contribuir para a compreensão das condições de acesso e permanência desses estudantes jovens com deficiência, mediante as dificuldades apontadas pelos sujeitos docentes e estudantes na experiência da vida em IES. Este artigo discute em um primeiro momento as políticas públicas para o ensino superior relacionadas à educação inclusiva com enfoque nos principais marcos legais. Aborda em seguida a formação docente e a prática pedagógica, bem como a prática pedagógica inclusiva e a aprendizagem do estudante com deficiência. O artigo finaliza com a análise acerca da visão de docentes e estudantes com deficiência acerca da vivência em universidade, os principais entraves e as possibilidades de superação.

\section{O jovem com deficiência nas instituições de ensino superior, as políticas públicas e a educação inclusiva}

De acordo com o Estatuto da Juventude (2013), no Brasil são considerados jovens os sujeitos com idades entre 15 e 29 anos. A despeito disso, considera-se esta fase da vida como

${ }^{2}$ Portal. Mec. Gov.br secretaria-de-educacao-especial-sp-598129159 
um processo com maior amplitude e relacionada ao contexto social em que os sujeitos vivem, o acesso aos direitos sociais, aos bens materiais e a própria inserção no mundo do trabalho. Destarte, jovens trabalhadores, estudantes, da zona rural ou urbana, com deficiência ou não, dentre outros marcadores, definem a diversidade que engloba a categoria juventude (ou juventudes). Esta é construída socialmente, não podendo ser definida apenas por critérios biológicos (DOUTOR, 2016).

Aqui enfocamos os jovens com deficiência cujo percurso de transição para a vida adulta, certamente se dá de maneira diversa dos demais. Estudos apontam trajetórias marcadas pela exclusão e discriminação e condição de existência que incluem analfabetismo, desemprego e pobreza (UNICEF, 2013). Nos interessa entender, deste estudo, a vivência do jovem que conseguiu ingressar nas instituições de ensino superior, suas principais dificuldades, apoios, tensões, como se dá sua relação com os docentes em sua prática pedagógica.

Para tanto, não poderíamos deixar de expor aqui as políticas públicas que tratam de questões que envolvem os jovens com deficiência inseridos no ensino superior. Iniciamos apontando um momento relevante relativo à segunda guerra mundial, na qual muitas pessoas que foram à luta retornaram às suas comunidades com deficiências físicas, visuais, auditivas ou até mentais (emocionais). Isso fez com que as próprias pessoas com deficiências e as famílias dessas vítimas procurassem seus direitos garantidos como cidadãos. De acordo com Loss (2018), foi dessa forma que em 1948 a Organização das Nações Unidas - (ONU) ratificou a luta com a Declaração Universal dos Direitos Humanos, tendo como princípio a liberdade, a dignidade e os direitos de todas as pessoas mencionadas na educação. Os direitos humanos são marcados por histórias de movimentos sociais organizados em especial às pessoas com deficiência. Como define Loss (2018), esses movimentos foram considerados os instrumentos internacionais orientadores para o reconhecimento de tais direitos. Alguns deles foram relevantes como o da Tailândia em 1990, na cidade de Jointiem, o evento ocorrido foi a Conferência Mundial de Educação para Todos e na Espanha em 1994, em Salamanca, ocorreu a Conferência Mundial sobre Necessidades Educativas Especiais.

Essas ocorrências foram marcadas pelas mudanças de paradigmas em relação à educação especial. A primeira conferência sinaliza a educação como preocupação mundial. E a segunda, teve ênfase pela elaboração da declaração denominada Salamanca que objetivou o reconhecimento das diferenças, o atendimento às necessidades de cada um, a promoção da aprendizagem, o reconhecimento da importância da "escola para todos" e a formação de professores. Diante deste cenário, no ano de 2008, foi estabelecida a Política Nacional 
Educação Especial na Perspectiva da Educação Inclusiva - PNEE ${ }^{3}$. Este movimento mundial pela educação inclusiva é uma ação política, cultural, social e pedagógica, que defende o direito de todos os estudantes de estarem juntos sem nenhum tipo de discriminação. Para melhor ratificar este processo legislativo e educativo apresentaremos um quadro apontando alguns documentos legais que asseguram a educação inclusiva no ensino superior:

Quadro 1: Legislação que assegura a educação inclusiva no ensino superior

\begin{tabular}{|c|c|c|}
\hline Ano & Documento & O que estabelece \\
\hline 1999 & Aviso circular do MEC 277/1996 & $\begin{array}{l}\text { Recomenda que as IES iniciem ações e } \\
\text { encaminhamentos em seus concursos vestibulares } \\
\text { destinadas aos candidatos com deficiência, } \\
\text { sobretudo bancas e comissões especiais. }\end{array}$ \\
\hline 1999 & Decreto 3.298/99 & $\begin{array}{l}\text { Regulamenta a Lei } 7.853 / 89 \text {, que dispõe sobre a } \\
\text { Integração da Pessoa Portadora de Deficiência, } \\
\text { consolida as normas de proteção e dá outras } \\
\text { providências. }\end{array}$ \\
\hline 1999 & Portaria MEC 1.679/99 & $\begin{array}{l}\text { Dispõe sobre os requisitos de acessibilidade a } \\
\text { pessoas portadoras de deficiência para instruir } \\
\text { processos de autorização e de reconhecimento de } \\
\text { cursos e de credenciamento de instituições. }\end{array}$ \\
\hline 2000 & Lei $10.098 / 00$ & $\begin{array}{l}\text { Estabelece normas gerais e critérios básicos para a } \\
\text { promoção da acessibilidade das pessoas com } \\
\text { deficiência ou mobilidade reduzida e dá outras } \\
\text { providências. }\end{array}$ \\
\hline 2001 & $\begin{array}{l}\text { Plano Nacional de Educação- } \\
\text { PNE, Lei } 10.172 / 01\end{array}$ & $\begin{array}{l}\text { Estabelece metas e objetivos para os sistemas de } \\
\text { educação no sentido de garantir o atendimento as } \\
\text { crianças com necessidades especiais, formação de } \\
\text { professores, acessibilidade e Atendimento } \\
\text { Educacional Especializado - AEE. }\end{array}$ \\
\hline 2001 & $\begin{array}{l}\text { Resolução do CNE/CEB n2, de } \\
11 \text { se setembro de } 2001\end{array}$ & $\begin{array}{l}\text { Institui Diretrizes Nacionais para Educação Especial } \\
\text { na Educação Básica. }\end{array}$ \\
\hline 2002 & Portaria do MEC 2.678/02 & $\begin{array}{l}\text { Estabelece diretriz e normas para uso do sistema } \\
\text { Braille. }\end{array}$ \\
\hline 2002 & Lei $10.436 / 02$ & $\begin{array}{l}\text { Dispõe sobre a Língua Brasileira de Sinais - Libras } \\
\text { e dá outras providências. }\end{array}$ \\
\hline 2004 & Lei 10.845/04 & $\begin{array}{l}\text { Institui o Programa de Complementação ao } \\
\text { Atendimento às Pessoas com Deficiência para que } \\
\text { tenham atendimento em instituições especializadas, } \\
\text { quando não integradas ao sistema de ensino. }\end{array}$ \\
\hline 2004 & Decreto 5.296/04 & $\begin{array}{l}\text { Regulamenta as Leis } 10.048 / 00 \text {, que dá prioridade } \\
\text { de atendimento às pessoas com deficiência e a } \\
10.098 / 00 \text {, que estabelece normas gerais e critérios } \\
\text { básicos para a promoção da acessibilidade das } \\
\text { pessoas com deficiência ou com mobilidade } \\
\text { reduzidas e dá outras providências. }\end{array}$ \\
\hline 2005 & Decreto $5.626 / 05$ & $\begin{array}{l}\text { Regulamenta as Leis } 10.436 \text { de } 24 \text { de abril de } 2002 \\
\text { que define a Libras (Língua Brasileira de Sinais) } \\
\text { como uma língua. E obriga o ensino de Libras nos } \\
\text { cursos de licenciaturas e fonoaudiologia. }\end{array}$ \\
\hline
\end{tabular}

3 PNEE- Política Nacional da Educação Especial- Público alvo da educação especial é constituído por pessoas com deficiência, transtornos globais do desenvolvimento e altas habilidades/superdotação. 


\begin{tabular}{|l|l|l|}
\hline 2007 & Decreto 6.094/07 & $\begin{array}{l}\text { Plano de Desenvolvimento da Educação- PDE que } \\
\text { tem como centralidade a preocupação em formar } \\
\text { professores para educação inclusiva, acessibilidade } \\
\text { arquitetônica em prédios escolares, acesso de } \\
\text { pessoas com deficiência no ensino superior e } \\
\text { monitoramento ao benefício de prestação } \\
\text { continuada (BPC). }\end{array}$ \\
\hline 2008 & $\begin{array}{l}\text { Política Nacional de Educação } \\
\text { Especial na Perspectiva da } \\
\text { Educação Inclusiva (PNEE) }\end{array}$ & $\begin{array}{l}\text { Odocumento retoma o marco histórico e normativo, } \\
\text { aponta dados estabelece o público alvo da } \\
\text { educação especial-inclusiva. }\end{array}$ \\
Lei 13.146/15 (LBI) & $\begin{array}{l}\text { Institui a Lei Brasileira de Inclusão da Pessoa com } \\
\text { Deficiência (Estatuto da Pessoa com Deficiência) }\end{array}$
\end{tabular}

Fonte: Adaptado de Loss (2018), ensino superior e inclusão: palavras, pesquisas e reflexões entre movimentos internacionais.

Os imperativos legais e normativos descritos acima afirmam o compromisso de acesso e permanência da pessoa com deficiência no ensino superior e, consequentemente, seus direitos à educação. Esses documentos foram considerados divisores de águas para promoção digna da participação da vida social das pessoas consideradas excluídas. Ainda temos com parâmetro e contribuição do Ministério da Educação e Cultura que salienta sobre as questões legais:

[...] desencadeada em defesa do direito de todos os alunos estarem juntos, aprendendo e participando, sem nenhum tipo de discriminação. A educação inclusiva constitui um paradigma fundamentado na educação concepção de direitos humanos. (BRASIL 2008 p. 5)

No ano de 2015, foi efetivada uma nova cultura da concepção inclusiva, a Lei Brasileira de Inclusão - LBI. Em seus artigos 27, 28 e 30 reafirmam o compromisso relacionado à educação inclusiva no Ensino Superior, reforçando que as Instituições de Ensino Superior (IES) tenham direcionamento e se organizem para ampliar ações afirmativas no sentido de materializá-lo.

É preciso entender que o processo histórico da pessoa com deficiência, mesmo com essa trajetória normativa e documental, tanto na sociedade como no sistema educacional ao longo do tempo foi doloroso e desafiador. Essas pessoas com necessidades educacionais especiais, atualmente, estão na condição inclusiva, isto é, fazem parte da ambiência acadêmica e, consequentemente, devem exercer sua cidadania de forma equânime e emancipatória.

Diante de tantas leis, decretos, normatizações tanto nacionais como internacionais, vale ressaltar que, a mudança de atitudes para com as pessoas com deficiência e o seu direito em ingressar no ensino superior, seja ela pública ou privada, ainda é uma conquista a ser concretizada. Nesse cenário, cabe refletir, como tem se constituído a trajetória desses 
estudantes? Se os docentes realmente têm contribuído para o desempenho em sua aprendizagem? Será que enfrentam barreiras discriminatórias?

Tendo em vista a complexidade do que está subjacente a todo este processo, esse é o desafio. Ao mesmo tempo em que é preciso ter o olhar voltado para o estudante com deficiência, há ainda o contexto institucional, o organizacional e o pedagógico que envolve o cotidiano destes sujeitos que precisam ser autônomos e capazes de pensar e agir segundo sua própria consciência e, assim, criarem condições emancipatórias.

\section{Formação docente e prática pedagógica}

Aqui fazemos um convite para lançarmos lentes mais prospectivas sobre o contexto da formação docente e das práticas pedagógicas. Desta forma, é relevante aprofundar sobre esta temática, tendo em vista o foco deste estudo e a urgência em possibilitar novos conhecimentos acerca das práticas pedagógicas inclusivas.

Destacamos que neste contexto estruturante social, as ações que envolvem a formação docente estão postas conforme Feldmann, Hage e Pereira (2015), em dois modelos: o normativo e o técnico. O modelo normativo é embasado em um ensino modelador de comportamentos, no qual o professor sempre foi visto como técnico que executa suas aulas de forma mecânica e rotineira. É considerado como repassador de teorias e ideias aprendidas em sua formação inicial. Normalmente é visto como um agente isolado das decisões e soluções de problemas vividos no cotidiano acadêmico. Esse modelo traz em seu bojo o conhecimento fragmentado e descontextualizado da vida, o que leva a não participação dos estudantes na sociedade, isto é, sentem-se meros expectadores.

O segundo modelo, o técnico, apresentado pelas autoras, aponta para a construção de um paradigma que percebe o docente como sujeito reflexivo sobre sua própria prática, como forma de redimensioná-la. A construção da identidade do profissional, baseada na perspectiva da pesquisa, investigação e da reflexão, perpassa a constituir o indivíduo em sua interação com o outro, na reflexão e crítica de si mesmo, alicerçando-se nos aspectos que compõem sua autonomia. Portanto, a prática docente no pensamento crítico envolve o movimento dinâmico e dialético entre o fazer e o pensar sobre o fazer.

Com base nessas apreciações, entendemos que, a partir do momento em que o docente começar a repensar sistematicamente sobre sua própria prática e saber que a reflexão é um instrumento que poderá ajudá-lo no desenvolvimento do pensamento e da ação, provavelmente encontrará, na amplitude da própria prática, a base para redimensioná-la. 
Segundo Feldmann, Hage e Pereira (2015),

Com base nestas reflexões, compreende-se, em primeiro lugar, a importância de o professor superar a dicotomia entre o saber e o fazer, entre a teoria e a prática, entre a educação e o ensino, como pressuposto para transformar-se em um investigador de sua prática já que essa atitude acentua seu compromisso com o avanço do conhecimento e com o seu aperfeiçoamento pessoal e profissional. (p. 68).

Portanto para as autoras, o comprometimento de seu papel enquanto profissional é com a própria ação educativa, isto é, com o seu fazer docente. Aquele profissional que não seja simplesmente o transmissor de conteúdo, mas sim, o que além de entender-se enquanto ser histórico e social, tenha uma visão do coletivo, das potencialidades e dos problemas que cercam a realidade. E que proporcione condições de fazer com que os estudantes também se constituam sujeitos deste processo educativo.

Conforme Garcia (1999),

O pensar sobre a ação não pode se dar num vazio. Essa atitude cria, por si mesma, a necessidade de resgatar da prática a teoria ou os fragmentos de teoria que a embasam. Assim, a prática de pensar na prática e de estudá-la leva o docente à percepção dessa e do conhecimento anterior que possuía da mesma e que, de modo geral, envolve um novo saber. Pode-se dizer, portanto, que este é um momento de extrema importância na formação do professor, pois permite o avanço sobre o seu fazer e sua ressignificação. (p. 73)

Diante do exposto, compreendemos que mais do que transmitir conteúdos preestabelecidos, o docente precisa refletir sua própria prática e sua formação, essas devem estar baseadas numa análise crítica de sua ação. Com isso, precisa entender a importância de buscar avanços, de compreender suas limitações e observar pontos que precisam de referências teóricas, inclusive para entender dinâmicas relacionadas às deficiências dos estudantes, a exemplo de como atender às necessidades dos estudantes surdos, cegos, com deficiência física e outros. Nesta concepção, o docente precisa reconhecer que é por meio da reflexão de sua ação que também construirá novas formas de fazer e de enfrentar os desafios diante de práticas pedagógicas inclusivas. Assim, o docente pode buscar na teoria fundamentos para refazer sua prática.

Quanto a concepção de prática pedagógica, Pimenta e Anastasiou (2014) apontam que é preciso requer abertura para novas formas de ensinar e aprender e isso demanda dialogicidade, que estimule a 'ensinagem'. Em seus argumentos, as autoras sinalizam que o 
ensino concebe uma relação de troca contínua entre o docente e o estudante no processo de ensino-aprendizagem.

Franco (2012), sinaliza que prática pedagógica se constitui de forma intencional para atender a demandas educacionais, voltadas à sociedade. E ainda, são formadas por vários fatores complexos que requerem adesão, negociação, decisão e estratégia.

Porém podemos afirmar, diante da exposição das autoras, que as práticas pedagógicas além de serem compreendidas em sua totalidade, devem ser desenvolvidas no coletivo sem imposição. Deste modo, é preciso que o docente esteja imbuído de sua responsabilidade social, pois a prática docente significa estar vinculada ao fazer pedagógico fundamentado e de forma intencional, por isso, insiste, busca, dialoga, mesmo com as dificuldades que encontra nos espaços de aprendizagens.

Conforme aponta Garcia (1994), é preciso considerar que as práticas de ensino precisam estar em consonância com o respeito às diferenças, tanto do sujeito como de seu ritmo de aprendizagem. E aos docentes frente ao seu papel, cabe facilitar a apreensão dos conhecimentos e considerar os fatores externos e significativos para, assim, impulsionar o processo de aprendizagem.

Esses conceitos sobre prática pedagógica apontada pelos autores supracitados suscitam a ressignificação de um novo conceito de prática pedagógica. Esse processo de ressignificação requer um repensar dos fazeres, das estratégias, das práticas em sala de aula. É preciso constituir diversas formas alternativas de exposição do assunto estudado, de estratégias, de recursos, e ainda, utilizar várias maneiras de conduzir uma explicação de um conteúdo, para que estes estudantes pratiquem o ato educativo, desenvolva suas potencialidades de forma compensatória e assim, construam seu próprio conhecimento.

Nesta concepção, o docente precisa reconhecer que é por meio da reflexão de sua ação que também construirá novas formas de fazer e de enfrentar os desafios diante de práticas pedagógicas inclusivas.

\section{Prática pedagógica inclusiva e aprendizagens dos estudantes jovens com deficiência}

No contexto das práticas pedagógicas inclusivas, a interação social do coletivo dá consistência para que as ações se consolidem, tanto para o docente como para os estudantes com deficiência.

Ademais é importante considerar a natureza do seu fazer didático, pois o docente encontra heterogeneidade nas classes em que leciona e conforme indicam Calheiros e Fumes 
(2016), mesmo com fragilidades na formação inicial para atender às demandas do processo educacional inclusivo, o docente precisa buscar recursos e esforços próprios para suprir as necessidades do estudante, mesmo que por vezes não haja suporte institucional.

Sobre esse cenário, do ingresso do estudante jovem com deficiência no ensino superior, é importante destacar que quanto maior a obrigação legal de comprometimento e ações diferenciadas, maior será a inserção do docente neste processo inclusivo. Isso poderá ser uma das consequências da formação desses profissionais, pois, apesar da educação superior exercer papel fundamental na sociedade, ainda há uma lacuna em programas ou projetos que envolvam ações relacionadas à qualificação de seu corpo docente (formação continuada) para propostas mais arrojadas em relação à educação inclusiva.

Portanto, promover uma educação considerada inclusiva não é apenas uma questão de encontrar profissionais ou recursos diferentes, mas, sobretudo, lançar um novo olhar sobre as práticas pedagógicas, a equipe e os recursos disponíveis, por meio de um trabalho coletivo e de estratégias reflexivas, compreendendo que de acordo com Rodrigues, 2008, “[...] o professor é o principal recurso no qual a educação inclusiva deve se apoiar [...]". Ele é o agente mediador e moderador do processo de aprendizagem, cabendo-lhe a tarefa de acolher, planejar e executar as melhores e mais adequadas condições para a apropriação do conhecimento de todos os estudantes.

Essa reflexão nos leva a pensar na estreita relação entre as práticas docentes e em sua formação, haja visto que, a prática pedagógica inclusiva requer um profissional que atue frente às diversidades. Além disso, espera-se desse docente, que seja capaz de dominar estratégias dinâmicas de ensino, novas tecnologias da informação e comunicação e trabalhar de forma a atender a todos os estudantes.

Para isso, é preciso que o docente compreenda o currículo como algo dinâmico, alterável, passível de ampliação, de modo a possibilitar que todos compartilhem os mesmos conhecimentos utilizando-se de formas para acessar, interagir, construir e expressar esses saberes. Não se trata de elaborar um currículo novo ou diferente, mas, de ter um currículo acessível para que atenda realmente a todos os estudantes. Como afirma Correia (2016, p. 79), "a transformação das práticas pedagógicas é para todos os alunos, de modo a possibilitar que todos compartilhem dos mesmos conhecimentos". Este currículo acessível deve perpassar pela percepção do docente em acreditar na potencialidade dos estudantes. Implica ainda no planejamento pedagógico e nas ações docentes fundamentadas em critérios que definam, o que o estudante deve aprender, como e quando aprender; que formas de organização de ensino são mais eficientes para o processo de aprendizagem, e como avaliar. 
E, assim, possa realmente ressignificar o conceito de educação inclusiva, fazer com que a alteridade seja vista dentro de um prisma de semelhança e respeito às diferenças, tendo a igualdade como princípio básico e universal.

\section{Atuação dos docentes e a percepção dos estudantes com deficiência acerca de sua vivência em duas instituições de ensino superior da cidade de barreiras - Bahia}

Considerando que o problema deste estudo está relacionado com a investigação da formação docente e das práticas pedagógicas no processo de inclusão do estudante jovem com deficiência no Ensino Superior, elegemos a abordagem qualitativa para realização do estudo de caso. Quanto ao estudo, foi realizado em duas Instituições de Ensino Superior, uma privada e outra pública, localizada no Município de Barreiras/BA, Região Oeste da Bahia, no qual ouvimos docentes e estudantes jovens entre 20 a 29 anos. Buscamos compreender por meio de entrevistas em profundidade, como ocorre a formação docente e as práticas pedagógicas no processo de inclusão dos estudantes com deficiência e, também, como estes estudantes vivenciam a universidade.

Os sujeitos pesquisados nas duas IES, foram num total de 21 (vinte e um) docentes, sendo que ministraram aula para estudantes jovens com deficiência e 11 (onze) estudantes com deficiência. Em relação à escolha dos docentes, esta realizou-se a partir da indicação dos responsáveis pelos programas que orientam os docentes e estudantes com deficiência e necessidades especiais PROANE $^{4}$ e NAI. $^{5}$

Apresentaremos a seguir, os resultados deste estudo, lembrando que os participantes sinalizam aspectos diversos, os quais foram distribuídos em categorias constantes nos quadros- síntese. Vale ressaltar que alguns participantes tiveram suas respostas distribuídas em mais de uma categoria, por isso, em alguns momentos, a quantificação não corresponde exatamente a quantidade de participantes, mas à variedade das respostas.

A primeira indagação que fizemos aos docentes foi em relação a: sua concepção em relação à educação inclusiva, da qual obtivemos as mais variadas respostas tanto dos docentes da IES privada quanto a da pública, que seguem no quadro 2 :

\footnotetext{
${ }^{4}$ Programa de atendimento os acadêmicos com necessidades especiais - IES privada

${ }^{5}$ Núcleo de Acessibilidade e inclusão - IES pública
} 
Quadro 2 - Concepção dos docentes em relação a educação inclusiva

\begin{tabular}{|c|c|c|c|c|}
\hline \multicolumn{5}{|c|}{ RESPOSTAS / NÚMERO DE PARTICIPANTES } \\
\hline $\begin{array}{c}\text { Criar condições de } \\
\text { equidade }\end{array}$ & $\begin{array}{c}\text { Adquirir } \\
\text { experiência }\end{array}$ & $\begin{array}{c}\text { Facilitar } \\
\text { aprendizagem }\end{array}$ & $\begin{array}{c}\text { Adaptar às } \\
\text { metodologias }\end{array}$ & $\begin{array}{c}\text { Não domina nada } \\
\text { de educação } \\
\text { inclusiva }\end{array}$ \\
\hline 3 & 2 & 2 & 3 & 1 \\
\hline $\begin{array}{c}\text { Criar condições de } \\
\text { equidade }\end{array}$ & $\begin{array}{c}\text { Falta formação } \\
\text { sobre educação } \\
\text { inclusiva }\end{array}$ & $\begin{array}{c}\text { Não domina nada de } \\
\text { educação inclusiva }\end{array}$ & - & - \\
\hline 9 & 3 & 3 & - & - \\
\hline
\end{tabular}

Fonte: Elaboração própria, 2019.

A questão acima, sobre a concepção dos docentes em relação à educação inclusiva percebemos nas respostas dos docentes das duas IES que o conceito de educação inclusiva ainda não é claro para os docentes. Uma das respostas que nos chamou atenção foi sobre "facilitar a aprendizagem" e "falta formação sobre educação inclusiva". Essas respostas sinalizam que, promover uma educação considerada inclusiva não é apenas uma questão de facilitar aprendizagem e nem de encontrar profissionais ou recursos diferentes, mas, sobretudo, lançar um novo olhar sobre as práticas pedagógicas, a equipe e os recursos disponíveis, por meio de um trabalho coletivo e de estratégias reflexivas, compreendendo que de acordo com Rodrigues (2008, p. 11) “[...] o professor é o principal recurso no qual a educação inclusiva deve se apoiar [...]". Portanto, ele é o agente mediador e moderador do processo de aprendizagem. Essa reflexão nos leva a pensar na estreita relação entre as práticas docentes na sua formação, haja vista que a prática pedagógica inclusiva requer um profissional que atue frente às diversidades.

Selecionamos abaixo algumas falas dos docentes que sinalizam a respeito do que conhecem sobre educação inclusiva e de sua formação acadêmica.

Minha concepção considero bastante rasa, porque eu tive poucas oportunidades durante a minha formação de entrar nessa área da inclusão. Mesmo com uma formação em licenciatura, não foi suficiente. A formação do professor é muito deficitária. (Docente 1 - Curso de Bacharelado em Humanidades)

Em relação a educação inclusiva hoje a gente ainda tá engatinhando é muito precoce dizer que já existe educação inclusiva de forma ampla. (Docente 2 - Curso de Fisioterapia)

Eu não conheço a fundo como tem se dado a educação inclusiva no Brasil. Mas é fato que é uma necessidade que nós temos, muito grande, porque já não podemos tratar essas pessoas como se elas não existissem. (Docente 3 Curso de Direito) 
Outra questão que escolhemos para a pesquisa foi sobre entender qual sentimento em ser docente de estudante jovem com deficiência e o que isto provoca em você. O resultado segue no quadro 3 :

Quadro 3 - Sentimento que provoca em ser docente de estudante jovem com deficiência

\begin{tabular}{|c|c|c|c|}
\hline \multicolumn{5}{|c|}{ RESPOSTAS / NÚMERO DE PARTICIPANTES } \\
\hline \multicolumn{5}{|c|}{ IES PRIVADA } \\
\hline Desafio & Aprendizado & Reflexão & Respeito \\
\hline 2 & 2 & 2 & Despreparo \\
\hline \multicolumn{5}{|c|}{ IES PÚBLICA } \\
\hline Desafio & Aprendizado & Insegurança & 2 \\
\hline 6 & 3 & 3 & 2 \\
\hline
\end{tabular}

Fonte: Elaboração própria, 2019.

Nas respostas apresentadas pelos docentes, ficou evidente que para a maioria deles, ser docente de estudante jovem com deficiência é desafiador, isto é, incita novas formas de planejar e organizar suas aulas, mesmo que surjam inseguranças e reflexões. Importante salientar também que alguns docentes atribuem dar aula para estudantes com deficiência como aprendizado e respeito.

Segundo Rocha e Miranda (2017), para se efetivar a construção de uma educação inclusiva é preciso reestruturação dos sistemas de ensino e estes devem organizar-se para dar respostas às necessidades educacionais de todos os alunos. Essa finalidade requer ações práticas e viáveis que tenham como perspectiva operacionalizar a inclusão social e escolar de todas as pessoas, independentemente de suas necessidades.

Outro questionamos ainda aos docentes foi se tiveram: dificuldade em administrar suas metodologias para os estudantes jovens com deficiência e as respostas dos docentes das duas IES foram análogas. Segue resultado no quadro 4:

Quadro 4 - Dificuldade em administrar metodologias para os estudantes jovens com deficiência

\begin{tabular}{|c|c|c|c|}
\hline \multicolumn{5}{|c|}{ RESPOSTAS / NÚMERO DE PARTICIPANTES } \\
\hline \multicolumn{5}{|c|}{ IES PRIVADA } \\
\hline Teve dificuldade no início & Teve dificuldade & Não teve dificuldade & \\
\hline 2 & 4 & 2 & Teve preocupação \\
\hline \multicolumn{5}{|c|}{ IES PÚBLICA } & 2 \\
\hline Teve muita dificuldade & Teve dificuldade & Não teve dificuldade & 2 \\
\hline 3 & 6 & 2 & 2 \\
\hline
\end{tabular}

Fonte: Elaboração própria, 2019.

Nos resultados para esta questão, verificamos que a maioria dos docentes das duas IES, tiveram dificuldade em ministrar aulas para os estudantes jovens com deficiência. 
Sinalizamos a seguir algumas dificuldades relatada por eles. Por não saber como transmitir as informações da disciplina, como se comunicar com o estudante, como atender 2 (dois) tipos de deficiência diferentes em sala, e ainda, dificuldade por não terem sidos avisados da presença do estudante com deficiência na sala e ainda não ter sido orientado com antecedência como lidar com estes estudantes. Tivemos respostas em que os docentes, não tiveram dificuldade alguma, pois utilizaram de recursos do NAI (ampliação dos textos), da intérprete e colegas da sala, um dos docentes tentou se colocar no lugar do estudante e se aproximar dele e outro aprendeu como fazer com o próprio estudante. Outros disseram ter preocupação no início de como fazer, mas logo entenderam como trabalhar com o estudante com deficiência e sua especificidade.

De acordo com essas informações, percebemos que, a partir do momento em que o docente repensar sua prática e souber que a reflexão é um instrumento que poderá ajudá-lo no desenvolvimento do pensamento e da ação, provavelmente encontrará a base para redimensiona-la. Segundo Feldmann, Hage e Pereira (2015), o comprometimento de seu papel enquanto profissional é com a própria ação educativa, isto é, com o seu fazer docente. Aquele profissional que não seja simplesmente o transmissor de conteúdo, mas sim, o que além de entender-se enquanto ser histórico e social, tenha uma visão do coletivo, das potencialidades e dos problemas que cercam a realidade. E que proporcione condições de fazer com que os estudantes também se constituam sujeitos deste processo educativo.

Com isso, precisa buscar avanços, de compreender suas limitações e observar pontos que precisam de referenciais teóricos, inclusive para entender e atender as necessidades dos estudantes surdos, cegos, com deficiência física, intelectual e outras. Assim, trilhará por uma prática pedagógica inclusiva.

Em relação a questão investigada para os estudantes, foi relacionada à impressão e ou sensação deles ao ingressarem no ensino superior, lembrando que foi com mais de uma possibilidade de resposta. Os resultados da questão estão destacados no quadro 5.

Quadro 5 - Impressões/sensações do estudante ao ingressar no ensino superior

\begin{tabular}{|c|c|c|}
\hline \multicolumn{3}{|c|}{ RESPOSTAS / NÚMERO DE PARTICIPANTES } \\
\hline $\begin{array}{c}\text { Realização / sonho / } \\
\text { conquista }\end{array}$ & Medo / Insegurança & $\begin{array}{c}\text { Dificuldade por conta da deficiência } \\
\text { (de ordem técnica) }\end{array}$ \\
\hline 03 & 04 & 02 \\
\hline \multicolumn{2}{|c|}{ UFOB } \\
\hline Muito boa & $\begin{array}{c}\text { Dificuldade por conta da acessibilidade } \\
\text { atitudinal / Medo de bullyng }\end{array}$ & $\begin{array}{c}\text { Dificuldade por conta da deficiência } \\
\text { (de ordem técnica) }\end{array}$ \\
\hline 03 & 03 & 05 \\
\hline
\end{tabular}

Fonte: Elaboração própria, 2019. 
Percebemos que, tanto na FASB quanto na UFOB, os estudantes tiveram respostas semelhantes quais sejam: sensações de realização, sonho, medo, insegurança, dificuldade técnica (falta de intérprete de libras e recursos utilizados de acordo com a deficiência). Abaixo, sinalizamos algumas falas dos estudantes:

Bem, a minha primeira impressão, quando entrei na universidade e quando recebi a notícia de que fui contemplado com a vaga foi: primeiro que foi uma oportunidade que eu tava esperando e que eu vi ali uma luz que se abriu para que eu conseguisse superar minhas dificuldades (...) por mais que a gente saiba que há dificuldade, que há toda a problemática, eu, de imediato esperava encontrar um espaço, mais acessível. (Manelito, estudante com def. física)

Todos ficaram assustados, eu percebi a ansiedade neles, era um momento diferente, porque lidar com uma pessoa diferente não é normal né, você sente uma dificuldade de "como é que eu vou fazer"? Senti neles uma preocupação muito grande de me acolher e de me incluir na turma, (... ) apesar de não terem modos e meios de me incluir como deficiente porque tá todo mundo ainda aprendendo e eu também tô aprendendo a lidar com todo mundo, mas foi bom eu me senti mais aceita do que em outros ambientes.(Kati,, estudante com def. auditiva).

Ciantelli e Leite (2016, p.426), que estudaram os núcleos de acessibilidades de instituições públicas federais, analisaram que é preciso investir em ações de acessibilidade por meio de núcleos, pois estes envolvem toda a comunidade acadêmica. Para as autoras, tais núcleos deveriam ter a finalidade de ofertar informação e conhecimento sobre os diferentes aspectos que envolvam a inclusão da pessoa com deficiência na Educação Superior, como os dispositivos legais e as políticas, a revisão de regimentos e projetos político-pedagógicos e plano de desenvolvimento institucional, tornando assim, os espaços menos excludentes.

Percebemos que, o que mais ficou evidente nas narrativas dos estudantes das duas IES foi a questão do medo, insegurança, constrangimento, falta de acessibilidade. Somente um estudante relatou que se sentiu feliz.

Moreira (2014) afirma que, nestes casos, é inegável o papel social da universidade e de seu compromisso de não ser indiferente à desigualdade a todos os caminhos que busquem um processo educacional justo e democrático. Esse compromisso é também um resgate histórico, uma dívida pública que deve ser assumida conjuntamente entre o sistema e as políticas educacionais para que haja equalização de oportunidades.

Ao adentrarmos nas questões relacionadas às demandas pedagógicas, solicitamos aos estudantes que relatassem sobre como são desenvolvidas as ações metodológicas das aulas e 
se estas são adaptadas às suas necessidades. Em um universo de 11 (onze) estudantes entrevistados, obtivemos diversas respostas que apontamos no quadro 6

Quadro 6 - Ações metodológicas para atender as necessidades dos estudantes com deficiência

\begin{tabular}{|c|c|c|}
\hline \multicolumn{3}{|c|}{ RESPOSTAS / NÚMERO DE PARTICIPANTES } \\
\hline \multicolumn{3}{|c|}{ FASB } \\
\hline As vezes adaptavam & As vezes esqueciam & Adaptavam \\
\hline 02 & 03 & 02 \\
\hline As vezes adaptavam & Não adaptavam nada visual & Nenhuma adaptação especifica \\
\hline 06 & 01 & 02 \\
\hline
\end{tabular}

Fonte: Elaboração própria, 2019

O quadro 6 pode ser ilustrado nos relatos das estudantes, que apontam:

Não, porque quando tinha debate em sala eu não conseguia entender com clareza, por exemplo, precisava ter algo visual para o surdo, porque eu não conseguia entender só falando... falando... falando, eu não entendia. Então teria que ter algo visual. Agora sim que alguns professores começaram a adaptar algum material visual, porque ai eu posso entender melhor. E também depois que o NAI começou a cobrar as adaptações dos professores. (Gil, estudante com surdez)

Hoje sim, alguns materiais e provas, são ampliados e são adequados para minha deficiência. Mas somente alguns professores, porque alguns já me dão o material todo adequado, outros eu preciso passar pro NAI fazer a ampliação. (Sandi, estudante com baixa visão)

Mesmo com alguns relatos dos estudantes sendo positivos, entendemos que a ausência de um trabalho conjunto efetivo entre os núcleos de apoio e os docentes ainda é uma das barreiras a serem superadas no âmbito pedagógico. Portanto, este conjunto precisa entender que a adaptação pedagógica deve ser contínua e eficiente, só assim poderá favorecer o processo de aprendizagem desses estudantes. Isso pressupõe o desenvolvimento de ações solidárias, de compartilhamento de conhecimentos, de material de tecnologia assistiva, recursos e estratégias.

É preciso também considerar que as práticas de ensino precisam estar em consonância com o respeito às diferenças, tanto do estudante como de seu ritmo de aprendizagem. E aos docentes, cabe considerar os fatores externos significativos, para assim incentivar o processo de aprendizagem. 
Essas novas práticas requerem a ressignificação do conceito de prática pedagógica. Esse processo de ressignificação, requer um repensar dos fazeres, das estratégias, de ações metodológicas a serem desenvolvidas em sala de aula. É preciso constituir diversas formas alternativas de exposição do assunto estudado, de estratégias, de recursos, e ainda, utilizar várias maneiras de conduzir uma explicação de um conteúdo, para que todos os estudantes pratiquem o ato educativo, desenvolva suas potencialidades de forma compensatória e assim, construam seu próprio conhecimento.

Isso se faz presente na educação inclusiva, pois no interior desse processo, a condição dos sujeitos (docentes e estudantes) desses aprendizados está ligada às práticas sociais, institucionais e pessoais. Portanto, é de acordo com a concepção que se tem dessas práticas que o docente poderá contribuir com as barreiras que impedem ou restringem a aprendizagem, desempenho e permanência dos estudantes com deficiência.

\section{Considerações finais}

Ao estudarmos e analisamos sobre o mote, "formação docente e prática pedagógica no processo de inclusão de estudante jovem com deficiência, exigiu-nos uma postura analítica e reflexiva apoiada em leituras dos pressupostos, legais e histórico do ensino superior, da educação da pessoa com deficiência e ainda da formação docente e das práticas pedagógicas. Essa reflexão e análise se constituíram na tentativa de compreender como ocorre a formação docente e a prática pedagógica no processo de inclusão do estudante com deficiência nas instituições de ensino superior do município de Barreiras BA, a partir das vozes dos sujeitos pesquisados. E ainda como desdobramento deste objetivo, propusemos, identificar qual a concepção que os docentes apresentam acerca da educação inclusiva, bem como, investigar qual o sentimento dos docentes ao se depararem com estudantes com deficiência em sua sala aula e analisar se os docentes tiveram dificuldade em administrar metodologias para os estudantes com deficiência e por fim investigar como os estudantes jovens vivenciam a vida universitária.

$\mathrm{Na}$ trajetória da pesquisa, os docentes apontam para os significados que atribuem as suas trajetórias na docência em relação a sua formação e às práticas pedagógicas e ao processo de inclusão. Seus discursos apontam a falta de conhecimento a respeito da educação inclusiva, das práticas pedagógicas que poderiam se apropriar, e ainda, da inserção e permanência de pessoas com deficiência no ensino superior. Essa ausência de conhecimento, atribuída pelos docentes aqui amplamente compreendida é considerada como desafios 
enfrentados em seu percurso formativo que interfere nos modos do fazer pedagógico inclusivo. Do mesmo modo, revelam possibilidades para que suas experiências sejam capazes de suscitar novas perspectivas acerca de uma ação transformadora, das potencialidades pessoais e sociais dos estudantes com deficiência. Desta forma, essas práticas inclusivas, se compreendidas e aplicadas podem colaborar para o acesso, vivência e permanência do estudante com deficiência.

Os resultados da investigação revelam que os docentes e estudantes jovens passam por desafios em termos complexos do ensinar e aprender na perspectiva da educação inclusiva. Desta forma, os docentes precisam repensar e ressignificar sua ação educativa, neste contexto. Estas práticas pedagógicas, podem ser transformadas em força propulsora quando, estiverem voltadas à educação inclusiva, e estas se materializem. Além disso, esperase desse docente, que seja capaz de dominar estratégias dinâmicas de ensino, novas tecnologias da informação e comunicação e trabalhar de forma a atender a todos os estudantes.

Com isso, não se trata de elaborar um currículo novo ou diferente, mas que o docente compreenda o currículo como acessível, isto é, dinâmico, alterável, passível de ampliação, de modo a possibilitar que todos compartilhem os mesmos conhecimentos utilizando-se de formas para acessar, interagir, construir e expressar esses saberes.

No que tange aos estudantes, sua trajetória traz à tona a importância de fazer da universidade além de um espaço significativo de aprendizagem, também de troca e de formação de vínculos afetivos. A maioria deles apontam que a experiência positiva foi relativa ao relacionamento saudável com colegas e com alguns professores, seguido da adaptação metodológica e da adaptação dos docentes em relação às suas necessidades. Outras questões suscitadas foram relacionadas à importância do desempenho acadêmico, da acessibilidade e de estar inserido no ensino superior. Esses achados evidenciam que os itinerários formativos dos estudantes jovens com deficiência na universidade precisam ser construídos em estreita articulação com ações de respeito às diferenças, tendo a equidade como princípio básico e universal e a inserção de práticas pedagógicas inclusivas que venham ao encontro do acesso, permanência e desempenho. Essas ações devem permitir a esses estudantes experimentarem novas formas de autonomia e vivência acadêmica. Só assim, poderão representar o processo inclusivo no ensino superior e ter oportunidade de fortalecimento da afirmação pessoal e social.

É importante ressaltar que a problemática em estudo não se esgota nessa investigação, há um campo de possibilidades ainda vasto a ser explorado e que merece atenção daqueles 
que pretendem contribuir, por meio da pesquisa científica, com o delineamento de caminhos alternativos e que não ignoram o peso da inclusão educacional.

\section{REFERÊNCIAS}

BRASIL. Ministério da Educação. Política Nacional de Educação Especial na Perspectiva da Educação inclusiva, 2008

BRASIL. Estatuto da juventude. Brasília: Senado Federal. Coordenação de Edições Técnicas, 2013.

CALHEIROS; D.S.; Fumes, N.L.F. Experiências e saberes de professores universitários em relação à inclusão de alunos com deficiência na educação superior. Revista da FAEEBA: Educação e Contemporaneidade, v.25, n.46, p.239-255, 2016.

CORREIA, G. B. Deficiência conhecimento e aprendizagem. Uma análise relativa à produção acadêmica sobre Educação Especial e currículo. Dissertação (mestrado) - Programa de Pós-Graduação em Educação, Universidade Federal do Rio Grande do Sul, Porto Alegre, 2016.

Declaração Universal dos Direitos Humanos. UNIC / Rio / 005 - Dezembro 2000.

DOUTOR, C. Um olhar sociológico sobre os conceitos de juventude e de práticas culturais: perspectivas e reflexões. Última década, 45. Valparaíso: Ediciones CIDPA, 2016.

ESPANHA, MINISTERIO DE EDUCACIÓN Y CIENCIA ESPAÑA - Organización de las Naciones Unidas para la Educación, la Ciencia y la Cultura. Conferencia Mundial sobre Necesidades Educativas Especiales: Acceso y calidad. España: Salamanca, 1994. 49 p.

FELDMAN, Marian Graziela; HAGE, Maria do Socorro; PEREIRA, Ana Lúcia Nunes. As práticas pedagógicas e a formação docente: um elo a ser estreitado. Curitiba. CRV, 2015.

FERNANDES, C. M. B. Formação do professor universitário: tarefa de quem? In: MASETTO, M. (Org.). Docência Universitária. Campinas, Papirus, 1998, p. 95-112.

FRANCO, Maria Amélia do Rosário Santoro. Pedagogia e prática docente. 1 ed. São Paulo: Cortez, 2012.

GARCIA, C M. Formação de professores: para uma mudança educativa. Trad. Isabel Nascisa. Porto, Portugal: Porto Editora, 1999.

LOSS Adriana Salete, VAIN Daniel Pablo. Ensino Superior e inclusão: palavras pesquisas e reflexões entre movimentos internacionais. 1 ed.- Curitiba PR: CRV, 2018. 480p. (Coleção Ensino superior e inclusão, v.2)

MINAYO, Maria Cecília de Souza (org.). Pesquisa Social. Teoria, método e criatividade. 18 ed. Petrópolis: Vozes, 2009.

PIMENTA Garrido, Selma. ANASTASIOU, Camargo das Graças Léa. Docência no ensino superior. 5 ed. São Paulo: Cortez, 2014. 
REGIANI e MÓL, 2013 Revista educacional. PUC-Camp.Campinas,set./dez., 2017 p.130.

ROCHA e MIRANDA, 2006 Revista on line de Política e Gestão Educacional, v.21, n.1, p. 146-166, 2017.

RODRIGUES, David. Revista da Educação Especial. Brasília, v. 4, n. 2, p. 8-16, jul./out. 2008.

UNICEF. Children and Young people with disabilities. Disponível em: https://www.unicef.org/disabilities/files/Factsheet_A5 Web_REVISED.pdf. Acesso em 22 de fevereiro de 2020.

\section{SOBRE AS AUTORAS:}

\section{Patrícia Lessa Santos Costa}

Doutora em Ciências Sociais pela Universidade Federal da Bahia (UFBA). Professora da Universidade do Estado da Bahia (UNEB) Professora Permanente do Programa de Mestrado Profissional Gestão e Tecnologia Aplicadas à Educação (Gestec) e do Mestrado Profissional em Educação de Jovens e Adultos (MPEJA). E-mail: plessacosta@gmail.com.

(iD) http://orcid.org/0000-0002-2038-8132

\section{Nara Deoclecia Soares Modica}

Mestre da Universidade do Estado da Bahia (UNEB). Programa de Pós Graduação Stricto Sensu GESTEC da Universidade do Estado da Bahia ligado ao Departamento de Educação DEDC - Campus I. Membro do Grupo de Pesquisa Interculturalidades. Gestão da Educação e Trabalho (INTERGESTO). Defesa em 02/06/2020. E-mail: naramodica@ gmail.com

iD http://orcid.org/0000-0002-8250-3044

\section{Carla Liane Nascimento dos Santos}

Doutora em Ciências Sociais pela Universidade Federal da Bahia (UFBA). Professora Titular da Universidade do Estado da Bahia (UNEB), Professora Permanente do Programa de Mestrado Profissional Gestão e Tecnologia Aplicadas à Educação (Gestec) e do Mestrado Profissional em Educação de Jovens e Adultos (MPEJA), ambos na UNEB. Líder do Grupo de Pesquisa Interculturalidades. Gestão da Educação e Trabalho (INTERGESTO). E-mail: clnsantos@uneb.br

iD http://orcid.org/0000-0003-3964-5802 